\title{
Synthesis and Optical Characterization of Silver Doped Sodium Borate Glasses
}

\author{
Vandana Sharma $^{1}$, Supreet Pal Singh ${ }^{1}$, Gurmel Singh Mudahar ${ }^{1}$, Kulwant Singh Thind $^{2}$ \\ ${ }^{1}$ Department of Physics, Punjabi University, Patiala, India; ${ }^{2}$ Department of Physics, Guru Nanak Dev University, Amritsar, India. \\ Email: vandana@yahoo.com, spsingh@yahoo.com, gurmelmudahar@yahoo.com,kulwantsthind@yahoo.com
}

Received May $29^{\text {th }}, 2012$; revised July $5^{\text {th }}, 2012$; accepted July $16^{\text {th }}, 2012$

\begin{abstract}
Silver doped sodium borate glasses prepared by melt-quenching technique were checked by XRD technique for their amorphous nature. It is observed that the molar volume increases with increasing $\mathrm{Ag}_{2} \mathrm{O}$ content leading to open structure. Fourier Transform Infrared spectroscopy (FTIR) reveals the formation of $\mathrm{BO}_{3}$ and $\mathrm{BO}_{4}$ groups upon addition of silver oxide as modifier. From the Ultraviolet-Visible (UV-VIS) absorption spectra it is seen that the optical band gap increases with the increase of $\mathrm{Ag}_{2} \mathrm{O}$ content. Urbach energy is observed between $0.55-0.77 \mathrm{eV}$. The results obtained from molar volume, Fourier Transform Infrared spectroscopy and band gap energy measurements are in agreement with each other and nearly give the similar information about the studied glasses.
\end{abstract}

Keywords: Silver Doped Sodium Borate Glasses; Optical Band Gap; Molar Volume; UV-VIS and FTIR Spectroscopy and Bandgap Energy

\section{Introduction}

In recent years silver doped sodium borate glasses have attracted great attention because of their valuable optical properties and high value of ionic conductivity. They are considered to have potential applications in solid state batteries and electrochemical devices [1,2]. Glasses containing high concentration of transition metal ions are electronic conductors $[3,4]$. This classifies them as a form of amorphous semiconductors.

Borate glasses, based on $\mathrm{B}_{2} \mathrm{O}_{3}$ network may provide an alternative bioactive glass for biomedical applications [5]. Pure borate glass is made up of random network of boroxyl units with boron in three-fold co-ordination $\left(\mathrm{BO}_{3}\right)$. The addition of modifier helps in forming $\mathrm{BO}_{4}$ groups and non bridging oxygen, so increase of the non-bridging oxygen leads to open the network structure and the increase of durability [6,7]. The objective of this work is to through light into the optical characterization of silver ion doped sodium borate glasses by recording IR and UV-VIS spectra.

\section{Sample Preparation}

The synthesis of the glass samples $\left\{80 \% \mathrm{~B}_{2} \mathrm{O}_{3}-(20-y) \%\right.$ $\mathrm{Na}_{2} \mathrm{CO}_{3}-y \%$ AgO here $y=0.05,0.2,0.5$ and 1$\}$ was achieved by weighing the appropriate amounts of chemically reagent grade powders of $\mathrm{Ag}_{2} \mathrm{O}, \mathrm{Na}_{2} \mathrm{CO}_{3}$ and $\mathrm{B}_{2} \mathrm{O}_{3}$. The chemical composition (by weight) of the prepared glasses is listed in Table 1. The weighed batches were melted in porcelain crucibles in an electric furnace at temperatures ranging from $1000^{\circ} \mathrm{C}-1150^{\circ} \mathrm{C}$ for about 2 hours and rotated at interval to achieve homogeneity during the melting time. The homogenized molten glass was cast in graphite blocks. After quenching the glass, all the samples were immediately transferred to annealing furnace. All the samples were annealed at $400^{\circ} \mathrm{C}$.

\section{Experimental Techniques}

The amorphous nature of glass samples was confirmed with the help of X-Ray Diffraction (XRD) study using Rigaku Mini-flex Table Top spectrometer with $\mathrm{Cu}-\mathrm{K} \alpha$ line of wavelength $\lambda=1.5418 \AA$ at the scanning rate of $2^{\circ} / \mathrm{min}$ and $2 \theta$ was varied from $10^{\circ}$ to $80^{\circ}$. Infrared absorbance spectra of glass samples were taken in the range $500-2500 \mathrm{~cm}^{-1}$ using $\mathrm{KBr}$ technique at room temperature. A recording spectrometer of type Perkin-Elmer 1600 was used. The UV-VIS absorbance measurements

Table 1. Composition of prepared glass samples (by weight).

\begin{tabular}{cccc}
\hline Sample No. & $\mathrm{Ag}_{2} \mathrm{O}(\%)$ & $\mathrm{Na}_{2} \mathrm{CO}_{3}(\%)$ & $\mathrm{B}_{2} \mathrm{O}_{3}(\%)$ \\
\hline 1 & 0.05 & 19.95 & 80 \\
2 & 0.2 & 19.80 & 80 \\
3 & 0.5 & 19.50 & 80 \\
4 & 1 & 19 & 80 \\
\hline
\end{tabular}


were also performed to obtain the direct bandgap, indirect bandgap and Urbach energy values for the prepared glass samples.

FTIR absorption spectra were recorded at room temperature by using a spectrometer of type Shimadzu (Japan) FTIR-8700. The spectra obtained were used to analyze the structure of glasses.

The density of glass samples at room temperature was measured by the standard principle of Archimedes using a sensitive microbalance with pure benzene as the immersion fluid. The density was calculated according to the known formula.

$$
d=\frac{W_{a}}{\left(W_{a}-W_{b}\right) \times D}
$$

where $W_{a}$ is the weight of the sample in air, $W_{b}$ is the weight of the sample in benzene and $D$ is the density of buoyancy at room temperature. All the measurements were made using a digital balance (M/S Sartorius, model BP 221S, USA). The experiment was repeated five times to get an accurate value of density. The overall accuracy in the density measurements was $\pm 0.5 \mathrm{~kg} \cdot \mathrm{m}^{-3}$ and hence,

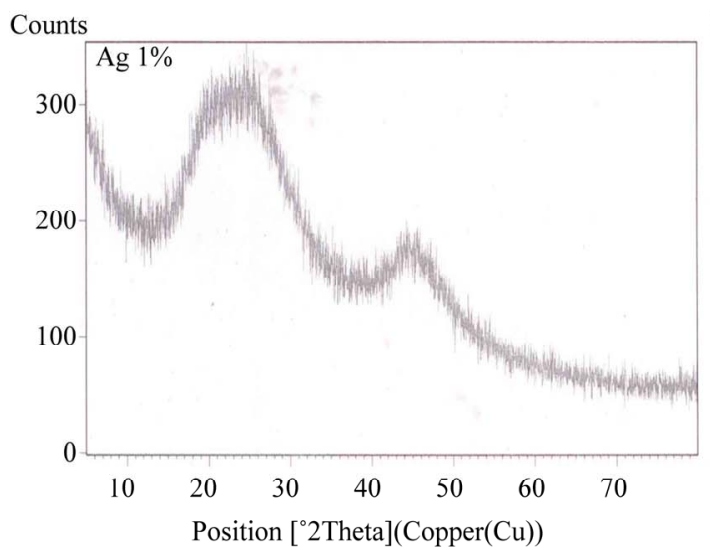

(a)

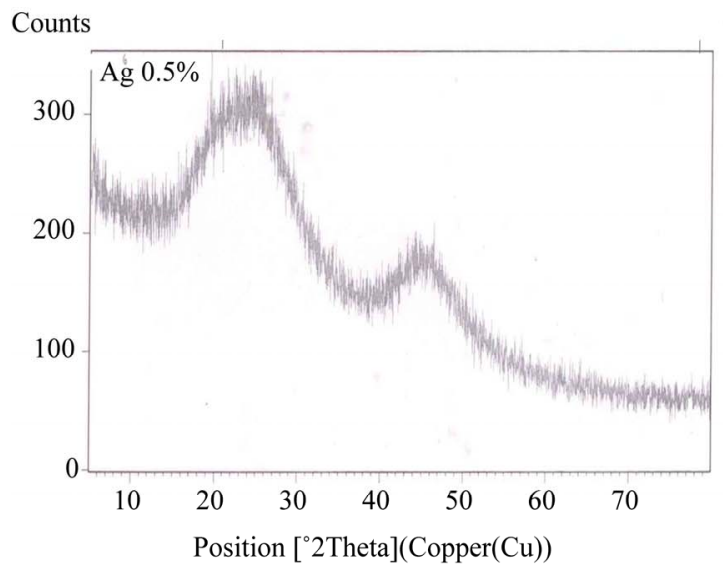

(c) the percentage error in the measurements of density was $\pm 0.006 \mathrm{~g} \cdot \mathrm{cm}^{-3}$.

The molar volume values were calculated by using the obtained densities and weight of one mole of the sample, with the help of the following equation:

$$
V_{m}=\sum_{i} \frac{M_{i}}{d}
$$

$M_{i}$ denotes the molar mass of the glass and $M_{i}=C_{i} A_{i}$. Here $C_{i}$ and $A_{i}$ are the molar concentrations and molecular weights of the $i$ th component, respectively and $d$ is measured density.

\section{Results and Discussion}

From the above experimental measurements the obtained results are discussed as follow:

\subsection{X-Ray Diffraction Analysis}

The powder XR diffraction analysis of the samples (Figure 1) exhibits no detectable peaks thus confirms the proper preparation of glass samples.

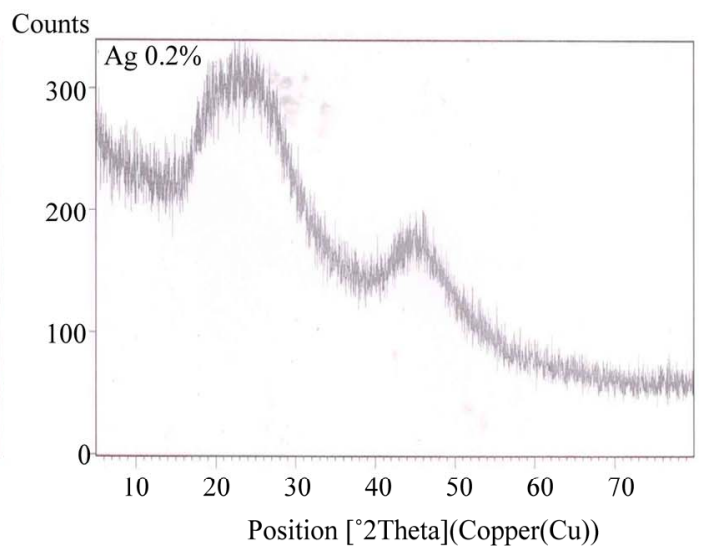

(b)

Counts

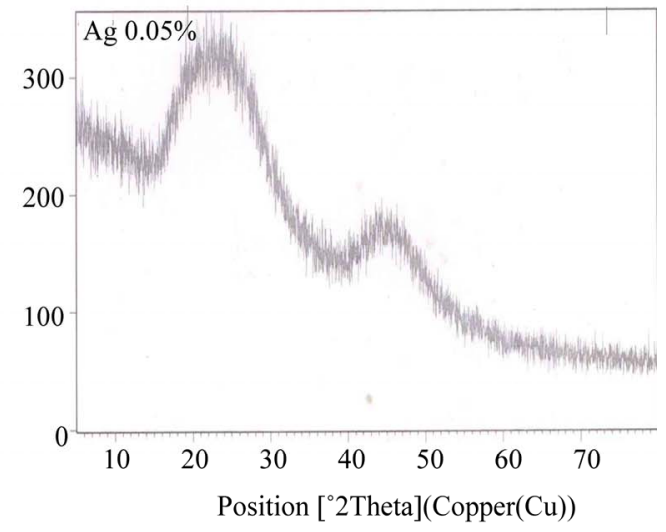

(d)

Figure 1. XRD of the glass samples with different contents of $\mathrm{Ag}_{2} \mathrm{O}$. (a) $1 \% \mathrm{Ag}_{2} \mathrm{O}$; (b) $0.2 \% \mathrm{Ag}_{2} \mathrm{O}$; (c) $0.5 \% \mathrm{Ag} 2 \mathrm{O}$; (d) $0.05 \%$ $\mathrm{Ag}_{2} \mathrm{O}$. 


\subsection{Molar Volume}

The molar volume of glasses is preferably used to describe the network structure and the arrangement of the building units, since it deals directly with the spatial structure of the oxygen network. The Molar volume indicates the spatial distribution of the oxygen in the glass network. The calculated molar volume values of the glass samples are shown in Table 2.

The increase in the molar volume with increasing content of $\mathrm{Ag}_{2} \mathrm{O}$ can be attributed to opening up of structure of glasses. It also reflects homogeneity of the network and reflects the strengthening of internal chemical bonds.

\subsection{FTIR Analysis}

The following information is required for structural analysis of oxide glasses [8]:

1) Type of the bridging bonds of oxygen which link the coordination polyhedra of framework and the composition of chemical inhomogeneities in the structure of glass;

2) The coordination number of the compound with respect to oxygen, especially of network formers;

3) The change in oxygen bonds of the framework, induced by the cation modifiers which combine with those bonds.

Moreover, the IR spectroscopy of borate containing compounds has vibrational modes mainly active in three infrared spectral regions $[9,10]$ :

1) The first group of bands occurring at $1200-1600$ $\mathrm{cm}^{-1}$ is due to asymmetric stretching relaxation of the $\mathrm{B}-\mathrm{O}$ bond of trigonal $\mathrm{BO}_{3}$ units;

2) The second group occurs at $800-1200 \mathrm{~cm}^{-1}$ is due to $\mathrm{B}-\mathrm{O}$ bond stretching of the tetrahedral $\mathrm{BO}_{4}$ units;

3) The third group occurring at around $700 \mathrm{~cm}^{-1}$ is due to bending of B-O-B linkages in the borate networks.

Predominantly 6 bands are observed in the glass samples (Figure 2). The band $535-550 \mathrm{~cm}^{-1}$ may be due to vibrations of sodium cations through the glass network. The band $665-695 \mathrm{~cm}^{-1}$ can be attributed to bending vibrations of $\mathrm{BO}_{3}$ triangles and stretching vibrations of $\mathrm{BO}_{3}$ units with non bridging oxygens respectively [11-14]. The band that appears around $1050 \mathrm{~cm}^{-1}$ can be due to stretching of the $\mathrm{BO}_{4}$ structural units [15]. The band around $1450 \mathrm{~cm}^{-1}$ can be assigned to B-O stretching vibrations and is mainly the linkage between oxygen and different groups as well as B-O bridging between boroxol

Table 2. The molar volumes of glass samples with different $\mathrm{Ag}_{2} \mathrm{O}$ content.

\begin{tabular}{lcccc}
\hline Sample No. & 1 & 2 & 3 & 4 \\
\hline $\mathrm{Ag}_{2} \mathrm{O}(\%)$ & 0.05 & 0.2 & 0.5 & 1 \\
Mol. Vol. $\left(\mathrm{cm}^{-1}\right)$ & 35.85 & 37.52 & 39.20 & 42.83 \\
\hline
\end{tabular}

rings and trigonal $\mathrm{BO}_{3}$ [16-18]. The bands at around $1630 \mathrm{~cm}^{-1}$ and $2333 \mathrm{~cm}^{-1}$ are attributed to $\mathrm{O}-\mathrm{H}$ bending that give rise to absorption in this region and the possibility of some adsorbed water [19,20].

\subsection{Optical Band Gap}

Analysis of optical spectra is one of the most beneficial tools to figure out the electronic structure of amorphous semiconductors [21]. Two types of optical transitions, i.e. direct and indirect, occur at the absorption edge [22]. The absorption coefficient, below and near the edge of each curve has been determined at different wavelengths using relation:

$$
\alpha(v)=\left(\frac{1}{t}\right) \ln \left(\frac{I_{0}}{I_{t}}\right)
$$

where $I_{0}$ and $I_{t}$ are intensities of the incident and transmitted beams, respectively and $t$ corresponds to thickness of each sample. Optical band gaps were calculated using absorption spectra for direct and indirect transitions for all prepared glass samples.

For direct transitions:

$$
\alpha(v)=B\left(h v-E_{o p t}\right)^{n} / h v
$$

where $n=1 / 2$ for allowed transitions, $B$ is a constant and $E_{\text {opt }}$ is direct optical band gap.

Above relation is also used for indirect transitions. In this case, $n=2$ for allowed transitions, $B$ is a constant and $E_{\text {opt }}$ is indirect optical band gap. By plotting $(\alpha h v)^{1 / 2}$ and $(\alpha h v)^{2}$ as a function of photon energy $h v$, optical band gaps for indirect and direct transitions can be determined respectively. The respective values of $E_{\text {opt }}$ were obtained by extrapolating to $(\alpha h v)^{1 / 2}=0$ for indirect transitions and $(\alpha h v)^{2}=0$ for direct transitions [23].

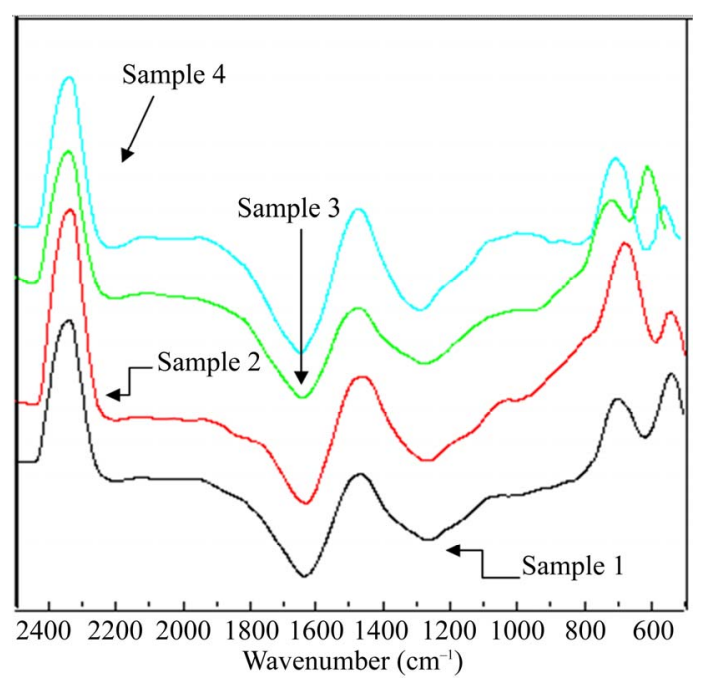

Figure 2. FTIR spectra of various glass samples with different contents of $\mathrm{Ag}_{2} \mathrm{O}$. 
Urbach energy values $(\Delta E)$ were calculated by taking the reciprocals of the slopes of linear portion in the lower photon energy region of these curves as stated with relation (4) [24].

$$
\alpha(v)=\alpha_{0} \exp (h v / \Delta E)
$$

Figures 3-5 show the plots for direct band gap, indirect band gap and Urbach energies for the present samples and their values are listed in Table 3. It is noticed that $E_{\text {opt }}$ increases with increasing $\mathrm{Ag}_{2} \mathrm{O}$ content. There must be some change in bonds which is reflected by lowering of band gap values. The noticed change may also arise from the photon-lattice interaction [25]. The shift of the absorption band to the higher energy corresponds to the increase in NBO's making the structure open. This also is in accord with our results for molar volume which also show an increase confirming the opening up of structure.

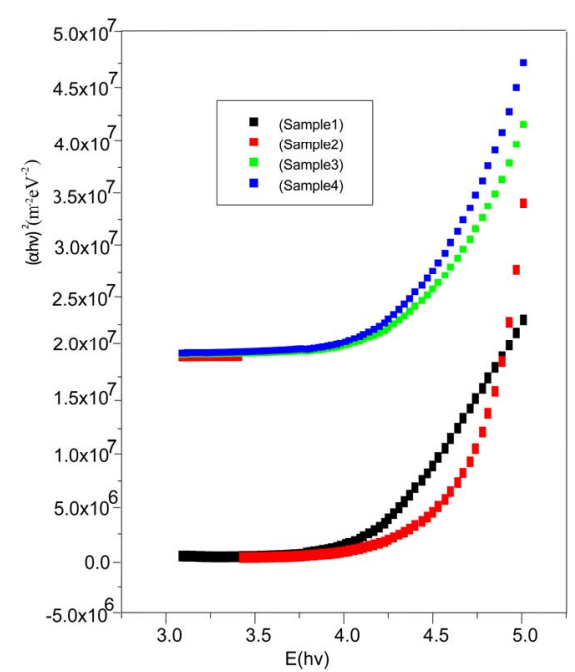

Figure 3. Plot of $E_{o p t}$ vs $(\alpha h v)^{2}$ for calculating direct band gap.

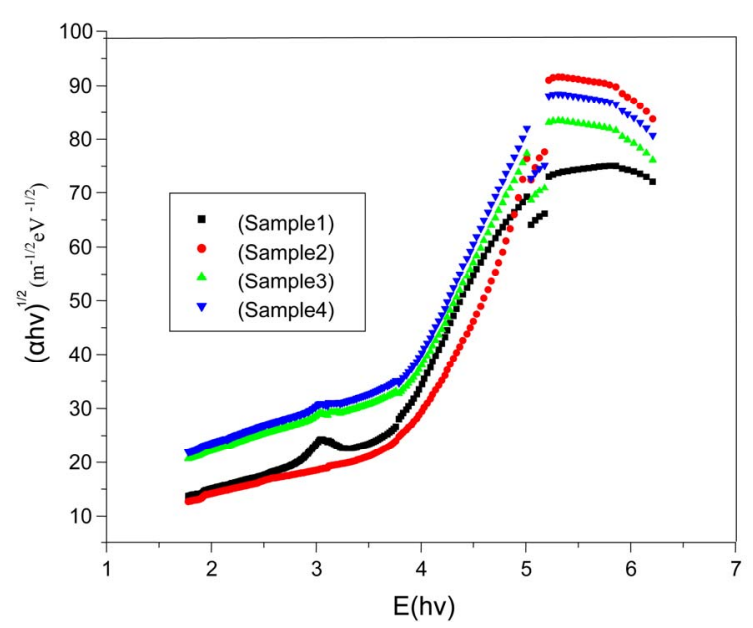

Figure 4. Plot of $E_{\text {opt }}$ vs $(\alpha h v)^{1 / 2}$ for calculating indirect band gap.

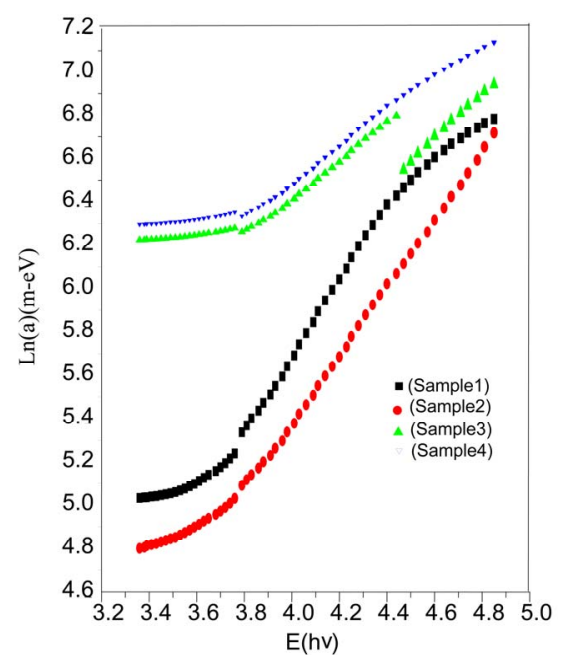

Figure 5. Plot of $E_{\text {opt }}$ vs $\ln \alpha$ for calculating Urbach energy.

Table 3. Direct, indirect bangap values and the Urbach energies for various $\mathrm{Ag}_{2} \mathrm{O}$ contents.

\begin{tabular}{lcccc}
\hline Sample No. & 1 & 2 & 3 & 4 \\
\hline $\mathrm{Ag}_{2} \mathrm{O} \%$ & 0.05 & 0.2 & 0.5 & 1 \\
Direct bandgap (eV) & 4.22 & 4.31 & 4.31 & 4.45 \\
Indirect bandgap (eV) & 3.14 & 3.23 & 3.25 & 3.32 \\
Urbach energy (eV) & 0.56 & 0.56 & 0.71 & 0.77 \\
\hline
\end{tabular}

\section{Conclusion}

The prepared samples are found to be in pure non crystalline phase. The molar volumes of the prepared samples increase gradually with increase of $\mathrm{Ag}_{2} \mathrm{O}$ content and appear to decrease due to closing up of structure of glasses. The groups like $\mathrm{BO}_{3}$ and $\mathrm{BO}_{4}$ act as network structural groups while sodium and silver appear in interstitial positions. From the Ultraviolet-Visible (UV-VIS) absorption spectra it is seen that the optical band gap increases with the increase of $\mathrm{Ag}_{2} \mathrm{O}$ content. Urbach energy is observed between $0.55-0.77 \mathrm{eV}$.

\section{REFERENCES}

[1] C. A. Angell, "Fast Ion Motion in Glassy and Amorphous Materials," Solid State Ionics, Vol. 9-10, 1983, pp. 3-16. doi:10.1016/0167-2738(83)90206-0

[2] S. Chandra and S. S. Sekhon, "Mixed Cation Effect in Silver Borate Ion Conducting Glass," Journal of Materials Science, Vol. 34, 1999, p. 2899.

[3] L. Murawski, C. H. Chung and J. D. Mackenzie, "Electrical Properties of Semiconducting Oxide Glasses," Journal of Non-Crystalline Solids, Vol. 32, No. 1-3, 1979, pp. 91-104. doi:10.1016/0022-3093(79)90066-8

[4] M. Sayer, A. Mansingh, M. Pollak, et al., "Noncrystalline Semiconductors," CRC Press, Boca Raton, 1987. 
[5] H. S. Ryu, J. K. Lee, J. H. Seo, H. Kim, K. S. Hong, D. J. Kim, J. H. Lee, D. H. Lee, B. S. Chang, C. K. Lee and S. S. Chung, "Novel Bioactive and Biodegradable Glass Ceramics with High Mechanical Strength in the CaO$\mathrm{SiO}_{2}-\mathrm{B}_{2} \mathrm{O}_{3}$ System," Journal of Biomedical Materials Research Part A, Vol. 68, No. 1, 2004, pp. 79-89. doi:10.1002/jbm.a.20029

[6] M. Sharma, K. S. Thind, G. Sharma, V. Rajendran, K. Singh, A. V. Gayathri-Devi and S. Aravindan, "Structural and Acoustic Investigations of Calcium Borate Glasses," Physica Status Solidi (A), Vol. 203, No. 10, 2006, pp. 2356-2364. doi:10.1002/pssa.200622140

[7] M. Pal, B. Roy and M. Pal, "Structural Characterization of Borate Glasses Containing Zinc and Manganese Oxides," International Journal of Modern Physics, Vol. 2, 2006, p. 1062. doi:10.4236/jmp.2011.29129

[8] L. Stoch and M. Sroda, "Infrared Spectroscopy in the Investigation of Oxide Glasses Structure," Journal of Molecular Structure, Vol. 511-512, 1999, pp. 77-84. doi:10.1016/S0022-2860(99)00146-5

[9] N. A. Ghoneun, E. I. Batul, H. A. Abdel-Shafi and M. H. Azooz, "Synthesis and Characterization of Cadmium Doped Lead-Borate Glasses," Proceedings of Egyptian Conference of Chemistry, 1996, p. 162.

[10] A. A. Alemi, L. Kafi-Ahmadi and Sh. Karamipour, "Preparation and Characterization of Terbium Oxide Doped Sodium Tetraborate Glasses," Iranian Journal of Crystal and Minimum, Vol. 16, 2009, p. 1387.

[11] J. Krogh-Moe, "The Structure of Vitreous and Liquid Boron Oxide," Journal of Non-Crystalline Solids, Vol. 1, No. 4, 1969, pp. 269-284. doi:10.1016/0022-3093(69)90025-8

[12] E. I. Kamitsos, "Infrared Studies of Borate Glasses," Physics and Chemistry of Glasses, Vol. 44, No. 2, 2003, p. 79.

[13] E. I. Kamitsos, A. P. Patsis, M. A. Karakassides and G. D. Chryssikos, "Infrared Reflectance Spectra of Lithium Borate Glasses," Journal of Non-Crystalline Solids, Vol. 126, No. 1-2, 1990, pp. 52-67. doi:10.1016/0022-3093(90)91023-K

[14] I. Waclawska, "Glass Transition Effect of Amorphous Borates," Thermochimica Acta, Vol. 269-270, 1995, pp. 457-464. doi:10.1016/0040-6031(95)02566-9

[15] E. I. Kamitsos, M. A. Karakassides and G. D. Cryssikos,
"Vibrational Spectra of Magnesium-Sodium-Borate Glasses. 2. Raman and Mid-Infrared Investigation of the Network Structure," The Journal of Physical Chemistry, Vol. 91, No. 5, 1987, pp. 1073-1079. doi:10.1021/j100289a014

[16] S. G. Motke, S. P. Yawale and S. S. Yawale, "Infrared Spectra of Zinc Doped Lead Borate Glasses," Bulletin of Materials Science, Vol. 25, No. 1, 2002, pp. 75-78. doi:10.1007/BF02704599

[17] E. I. Kamitos, A. P. Patris, M. A. Karakassides and J. D. Chryssikos, "Infrared Reflectance Spectra of Lithium Borate Glasses," Journal of Non-Crystalline Solids, Vol. 126, No. 1-2, 1990, pp. 52-67. doi:10.1016/0022-3093(90)91023-K

[18] I. Ardelean and M. Toderas, "FTIR Structural Investigation of $3 \mathrm{~B}_{2} \mathrm{O}_{3} \cdot \mathrm{BaO}$ Glass Matrix Containing Manganese ions," Advanced Materials for Optics and Electronics, Vol. 8, No. 3, 2006, p. 1118.

[19] H. Scholze, "Gases and Water in Glass," Indiana Glass, Vol. 47, No. 11, 1966, p. 622.

[20] F. M. Ernsbjer, "Der Einbau Des Wassers in Glässern," Glastech Ber Glass Science Technology, Vol. 32, No. 3, 1959, p. 81.

[21] D. T. Pierce and W. E. Spicer, "Electronic Structure of Amorphous Si from Photoemission and Optical Studies," Physical Review B, Vol. 5, No. 8, 1972, pp. 3017-3029. doi:10.1103/PhysRevB.5.3017

[22] M. Altaf, M. A. Chaudhry and M. Zahid, "Study of Optical Band Gap of Zinc-Borate Glasses," Journal of Research (Science), Vol. 14, No. 2, 2003, pp. 253-259.

[23] R. P. S. Chakradhar, K. P. Ramesh, J. L. Rao and J. Ramakrishna, "Mixed Alkali Effect in Borate Glasses-EPR and Optical Absorption Studies in $x \mathrm{Na}_{2} \mathrm{O}-(30-x)-\mathrm{K}_{2} \mathrm{O}-$ $70 \mathrm{~B}_{2} \mathrm{O}_{3}$ Glasses Doped with $\mathrm{Mn}^{2+}$," Journal of Physics and Chemistry of Solids, Vol. 64, No. 4, 2003, pp. 641650. doi:10.1016/S0022-3697(02)00365-7

[24] K. Subrahmanyam and M. Salagram, "Optical Band Gap Studies on $(55-x) \mathrm{Na}_{2} \mathrm{O}-x \mathrm{PbO}-45 \mathrm{P}_{2} \mathrm{O}_{5}$ (SLP) Glass System," Optical Materials, Vol. 15, No. 3, 2000, pp. 181186. doi:10.1016/S0925-3467(00)00033-1

[25] H. E. Donya, H. M. El-Samman, A. El-Adawy, A. Hussein, A. R. El-Sersy and N. E. Khaled, "Optical Studies of Oxyfluoroborate Glasses," Proceedings of Tenth Radiation Physics \& Protection Conference, 2010, p. 135. 